\title{
Downregulated IGFBP7 facilitates liver metastasis by modulating epithelial-mesenchymal transition in colon cancer
}

\author{
YUANFEI LI ${ }^{1 *}$, YANFENG XI ${ }^{2 *}$, GUOQIANG ZHU ${ }^{3}$, JUNMEI JIA $^{4}$, HE HUANG $^{5}$, \\ YANYAN LIU ${ }^{1}$, YARONG GUO ${ }^{1}$ and LIXIN LIU ${ }^{6}$ \\ ${ }^{1}$ Department of Oncology, The First Clinical Hospital, Shanxi Medical University; ${ }^{2}$ Department of Pathology, \\ Shanxi Cancer Hospital; ${ }^{3}$ Department of Burn and Plastic, The 985 Hospital of The PLA; ${ }^{4}$ Department of Oncology, \\ The First Hospital, Shanxi Medical University; Departments of ${ }^{5}$ General Surgery and ${ }^{6}$ Gastroenterology and Hepatology, \\ The First Clinical Hospital, Shanxi Medical University, Tai'yuan, Shanxi 030001, P.R. China
}

Received March 5, 2019; Accepted July 26, 2019

DOI: $10.3892 /$ or.2019.7303

\begin{abstract}
Distant metastasis is a major cause of cancer-associated mortality in patients with colon cancer. Insulin-like growth factor binding protein 7 (IGFBP7) has been identified as a crucial inhibitor of human cancer. However, the role of IGFBP7 in the pathogenesis of metastatic colon cancer has not been investigated. In the present study, the expression of IGFBP7 in 81 pairs of colon cancer tissues and adjacent normal tissues were investigated using immunohistochemistry. Furthermore, 24 pairs of primary colon cancer and matched liver metastasis tissues were analyzed. LoVo cells with IGFBP7-knockdown and HT-29 cells with IGFBP7-overexpression were employed. The expression levels of E-cadherin, N-cadherin and Vimentin were quantified and compared. Significant alterations in the expression of IGFBP7 between late stage (III + IV) colon cancer and adjacent normal colonic mucosa were observed. $(\mathrm{P}=0.031)$. The association between IGFBP7 and epithelial-mesenchymal transition (EMT) markers were validated in primary colon cancer and matched liver metastasis tissues. The invasive front of liver metastatic colon tissues revealed reduced IGFBP7 expression. Additionally, knockdown of IGFBP7 in LoVo cells resulted in decreased E-cadherin, and increased $\mathrm{N}$-cadherin and Vimentin expression compared with the control group. Overexpression of IGFBP7 in HT-29 cells induced an upregulation of E-cadherin; however, the $\mathrm{N}$-cadherin and Vimentin levels were decreased. In conclusion, the results of the present study suggested that IGFBP7
\end{abstract}

Correspondence to: Professor Lixin Liu, Department of Gastroenterology and Hepatology, The First Clinical Hospital of Shanxi Medical University, 85 Jiefang South Road, Taiyuan, Shanxi 030001, P.R. China

E-mail: lixinliu6@hotmail.com

${ }^{*}$ Contributed equally

Key words: colon cancer, epithelial-mesenchymal transition, E-cadherin, IGFBP7, liver metastasis may prevent colon cancer metastasis by inhibiting EMT, and serves as a potential diagnostic marker and therapeutic target for patients with colon cancer.

\section{Introduction}

Distant metastasis is the leading cause of cancer-associated mortality in patients with colorectal cancer (CRC); $\leq 25 \%$ of patients have synchronous colorectal liver metastases (CLM) upon diagnosis (1). Such synchronous presentation has been associated with poor survival outcome (2). Thus, it is important to understand the molecular mechanisms underlying distant metastasis to aid developments in effective therapeutic strategies for treating metastatic CRC or preventing metastasis with adjuvant chemotherapy. A key event in the process of distant metastasis is epithelial-mesenchymal transition (EMT), which induces the invasive and metastatic abilities of tumor cells in various types of cancer, such as ovarian cancer (3), breast cancer (4), CRC (5) and is associated with poor prognosis (6). During the EMT process, cancer cells lose their expression of cellular adhesion proteins, including E-cadherin and $\gamma$-catenin, and acquire the expression of mesenchymal markers, such as vimentin and $\mathrm{N}$-cadherin (7). Loss of E-cadherin expression has been reported to be a hallmark of the EMT process (8).

Insulin-like growth factor(IGF) is a potent mitogen involved in normal growth and development. The growth-promoting and metabolic activities of IGFs are modulated by IGF factor binding proteins (IGFBPs) and their receptors (9). IGFBP7 has been reported as a tumor suppressor in carcinomas. For example, IGFBP7 exhibits certain tumor-suppressive functions in colon cancer as well as hepatocellular carcinoma $(10,11)$. Furthermore, low IGFBP7 expression was determined to be associated with poorly differentiated breast cancer tumors and higher-stage disease (12) when immunohistochemical and microarray analyses were used to identify IGFBP7 expression in tumor cells. The mechanism underlying the putative tumor-suppressor function of IGFBP7 requires further investigation. Previous findings suggested that epithelial IGFBP7 acts as an IGF-1/2 antagonist that inhibits IGF-1 receptor activation by binding to the receptor, thereby suppressing cell growth and survival (13). Although mounting evidence indicates the 
importance of IGFBP7 in various cancer types, systematic investigations into the role of IGFBP7 in the metastasis of human CRC to organs, such as the liver, are required.

The aim of the present study was to investigate the expression of IGFBP7 in colon cancer with liver metastasis (LM), and compare the expression of IGFBP7 between primary CRC (PC) and matched LM tissues. Furthermore, the potential mechanism was determined by analyzing the effects of IGFBP7 overexpression and knockdown on the expression of EMT-associated proteins, including E-cadherin, N-cadherin and Vimentin protein levels.

\section{Materials and methods}

Patients and tissue samples. A tissue microarray was purchased from Shanghai Xinchao Industry Co., Ltd. (Shanghai). The microarray contained formalin-fixed, paraffin-embedded colon adenocarcinoma tissues (90 CRC and 90 adjacent tumor tissues). Of these 81 pairs of colon cancer tissues and adjacent normal tissues were included, as medical record data were lacking for 9 subjects and were therefore excluded. In addition, 24 PC (primary colon cancer) and matched corresponding LM (liver metastasis) tissues were obtained from the Shanxi Tumor Hospital (Taiyuan, China) and The First Clinical Hospital of Shanxi Medical University (Taiyuan, China). All cases were diagnosed according to the Union for International Cancer Control (UICC) TNM Classification of Malignant Tumors. Two pathologists were blinded to the samples and analyzed all samples to confirm diagnosis. Written informed consent was obtained from all patients prior to enrolment. All the procedures were conducted in accordance with standard guidelines for the Study of Humans and were approved by the Research Ethics Committee of First Hospital of Shanxi Medical University.

Cell lines. HCT116, SW480, SW620, RKO, LoVo and Caco2 CRC cell lines were purchased from the American Type Culture Collection (Manassas) to analyze the expression of IGFBP7. Cells were cultured in Dulbecco's modified Eagle's medium (DMEM; Gibco; Thermo Fisher Scientific, Inc.) containing $10 \%$ heat-inactivated fetal bovine serum (Thermo Fisher Scientific, Inc.), penicillin (100 U/ml), streptomycin $(100 \mathrm{U} / \mathrm{ml})$ and sodium bicarbonate $(1.5 \mathrm{~g} / \mathrm{l})$ at $37^{\circ} \mathrm{C}$ in a humidified atmosphere of $5 \% \mathrm{CO}_{2}$.

Immunohistochemistry (IHC). Paraffin-embedded sections $(4 \mu \mathrm{m})$ were deparaffinized and treated with $0.3 \%(\mathrm{v} / \mathrm{v})$ hydrogen peroxide to block endogenous peroxidase activity. Then, heat-induced antigen retrieval was performed using $0.01 \mathrm{M}$ sodium citrate $(\mathrm{pH} 6.0)$ and $10 \%(\mathrm{v} / \mathrm{v})$ bovine serum albumin (Sigma-Aldrich; Merck KGaA) in PBS for $10 \mathrm{~min}$ at room temperature. Sections were then incubated overnight at $4^{\circ} \mathrm{C}$ with mouse monoclonal antibodies (1:50) against IGFBP7 (cat. no. ab74169; Abcam, Cambridge, UK), E-cadherin (cat.no. ab1416; Abcam), N-cadherin (cat. no. ab18203; Abcam) and Vimentin (cat. no. ab8069; Abcam) overnight at $4^{\circ} \mathrm{C}$. A streptavidin-biotin-peroxidase complex kit (SABC kit; Zymed) was used to detect the protein conjugates, according to the manufacturer's protocol. The sections were developed using a diaminobenzidine substrate (Sigma-Aldrich; Merck KGaA) and counterstained with hematoxylin. Negative controls (NCs) were run in parallel; however, PBS or mouse IgG1 (AMS/Immunokontact) was applied.

Evaluation of immunostaining. Subjective visual scoring of staining was used to assess the immunoreactivity of samples; scores were based on the proportion of positive tumor cells to total tumor cells (positivity, $\%$ ) as follows: 0 , negative or $<5 \%$; $1,5-25 \% ; 2,26-50 \% ; 3,51-75 \%$ and $4,>75 \%$ positive cells. The staining intensity was evaluated as 0 , negative; 1 , weak; 2 , moderate and 3 , intense. Providing the staining intensity was heterogeneous, and scoring was based on the greatest degree of intensity (14). As $>95 \%$ of tumor cells stained positively for IGFBP7 in all specimens, only immunostaining intensity scores were analyzed. For the analysis of E-cadherin expression, staining intensity scores were categorized as negative $(<5 \%)$ or positive ( $\geq 5 \%)$. For statistical analysis, scores of $0-7$ were considered to indicate low expression and scores of 8-12 were considered to indicate high expression. Staining analysis was conducted by two researchers independently without knowledge of patient clinical data and the presence of LM.

$R N A$ preparation and reverse transcription-quantitative polymerase chain reaction $(R T-q P C R)$. Total RNA was extracted from cultured cells or fresh frozen colon cancer tissues using TRIzol ${ }^{\circledR}$ reagent (Thermo Fisher Scientific, Inc.) according to the manufacturer's protocol. Total RNA $(1 \mu \mathrm{g})$ was reverse transcribed using Reverse ace qPCR RT Kit (Toyobo). The primers used in the present study are presented in Table I. A volume of $2.0 \mu \mathrm{l}$ of each diluted cDNA (1:20) was subjected to RT-qPCR in a final volume of $20 \mu \mathrm{l}$ containing $100 \mathrm{nM}$ of each specific primer and SYBR-Green Mix (Takara Biotechnology, Co., Ltd.). The thermocycling conditions as follows: Initial enzyme activation at $95^{\circ} \mathrm{C}$ for $2 \mathrm{~min}$, followed by 40 cycles of $95^{\circ} \mathrm{C}$ for $15 \mathrm{sec}$ and $60^{\circ} \mathrm{C}$ for $20 \mathrm{sec}$, and elongation at $72^{\circ} \mathrm{C}$ for $20 \mathrm{sec}$. The experiment was performed in triplicate, and the relative expression of IGFBP7 was calculated using the $2^{-\Delta \Delta \mathrm{Cq}}$ method (15) and normalized to a-tubulin.

Generation of stable IGFBP7 knockdown or overexpression. For short hairpin (sh)RNA-mediated IGFBP7 knockdown, the constructs (pLenti-1\#miR-EGFP) developed by The RNAi Consortium (Open Biosystems; Thermo Fisher Scientific, Inc.) were packaged into lentiviral particles and used to infect the LoVo cell line. Selection was conducted with puromycin (Invitrogen; Thermo Fisher Scientific, Inc.) at $1 \mu \mathrm{g} / \mathrm{ml}$. All the experiments were conducted according to local biosafety regulations. In order to induce IGFBP7 expression, IGFBP7 Lentifect lentiviral particles (GeneCopoeia, Inc.) were used to overexpress the protein in HT-29 cells. The infection and selection processes were performed as aforementioned. Cells without any treatment comprised the blank group, and negative control was the Lenti-EGFP-infected group.

Western blot analysis. Proteins were extracted from cells in a Triton-X lysis (1\% Triton-X, $50 \mathrm{Mm}$ Tris and $150 \mathrm{mM} \mathrm{NaCl}$ ) containing protease inhibitors (pepstatin, phenylmethane sulfonyl fluoride, aprotinin and leupettin) for $1 \mathrm{~h}$ in $4^{\circ} \mathrm{C}$. Cell lysates were centrifuged at $12,000 \mathrm{xg}$ for $20 \mathrm{~min}$ at $4^{\circ} \mathrm{C}$, and the 
Table I. Sequence primers used for RT-qPCR.

\begin{tabular}{ll} 
Gene & \multicolumn{1}{c}{ Primer sequence } \\
\hline h-a-tubulin-5' & 5'-ATATGTGGCCAGAGGGAAGT-3' \\
h-a-tubulin-3' & 5'-GGCTGTGTTTGTAGACTTGG-3' \\
h E-cadherin-5' & 5'-AATGCCGCCATCGCTTAC-3' \\
hE-cadherin-3' & 5'-TCAGGCACCTGACCCTTGTA-3' \\
hN-cadherin-5' & 5'-GTGCCATTAGCCAAGGGAATTCAGC-3 \\
hN-cadherin-3' & 5'-GCGTTCCTGTTCCACTCATAGGAGG-3 \\
hvimentin-5' & 5'-GTCCACTGAGTACCGGAGACA-3' \\
hvimentin-3' & 5'-CGAAGGTGACGAGCCATTT-3' \\
hIGFBP7-5' & 5'-TGGAACAAGGTAAAAAGGGGT-3' \\
hIGFBP7-3 & 5'-TGGTATTTCATGTAAGGCATAC-3'
\end{tabular}

protein concentration in the supernatant was determined using a bicinchoninic acid protein assay. Protein extracts $(50 \mu \mathrm{g})$ were separated by $10 \%$ SDS-PAGE and then transferred to a polyvinylidene difluoride membrane (Merck KGaA). The membrane was blocked with $5 \%$ skim milk and tris-buffered saline with Tween-20 (25 mM Tris- $\mathrm{HCl}, \mathrm{pH} 7.5,150 \mathrm{mM}$ $\mathrm{NaCl}$ and $0.05 \% \mathrm{v} / \mathrm{v}$ Tween-20) for $2 \mathrm{~h}$ at room temperature. Subsequently, the membrane was incubated with a goat anti-IGFBP7 antibody (cat. no. ab74169; Abcam) at $0.1 \mu \mathrm{g} / \mathrm{ml}$ $(1: 1,000)$, and antibodies against E-cadherin (cat. no. ab1416; Abcam), N-cadherin (cat. no. ab18203; Abcam) and Vimentin (cat. no. ab8069; Abcam) overnight at $4^{\circ} \mathrm{C}$. Tubulin was used for the normalization of protein expression. An electrochemiluminescent chromogenic substrate was used to visualize the bands, and Image Lab 5.0 software (Bio-Rad Laboratories, Inc.) was used for quantitative analysis.

Cell Counting Kit-8 (CCK-8) assay for the analysis of cell proliferation. Cell lines including HT29, HT-29 miRNA, LoVo and LoVo cells with IGFBP7 shRNA-mediated knockdown were cultured in DMEM with $10 \%$ FBS containing $1 \mu \mathrm{g} / \mathrm{ml}$ recombinant IGFBP7 for 6 days. A CCK-8 assay was conducted to analyze cell proliferation at days 0,1 , 2, 3, 4, 5 and 6 following treatment. Briefly, $5 \times 10^{3}$ cells were seeded into 96-well plates and cultured overnight in DMEM supplemented with $10 \%$ FBS; cells were then cultured at $37^{\circ} \mathrm{C}$ with $5 \% \mathrm{CO}_{2}$ for $24 \mathrm{~h}$. CCK-8 reagent $(10 \mu \mathrm{l}$; Dojindo Molecular Technologies, Inc.) was added to the maintenance cell medium at various time points and incubated at $37^{\circ} \mathrm{C}$ for an additional $2 \mathrm{~h}$. Absorbance values were determined using a microplate reader (Multiskan MK3; Thermo Fisher Scientific, Inc.) at $450 \mathrm{~nm}$.

Invasion assay. The invasion assay was performed using transwell culture chambers ( $8 \mu \mathrm{m}$ pores; Costar, Corning, NK, USA) according to the manufacturer's instructions. The upper chamber was loaded with $1 \times 10^{5}$ cells in $0.2 \mathrm{ml}$ serum-free medium, while $0.6 \mathrm{ml}$ medium containing $10 \% \mathrm{FBS}$ was loaded to the lower chamber. After incubation for $48 \mathrm{~h}$ at $37^{\circ} \mathrm{C}$ in a humidified atmosphere of $5 \% \mathrm{CO}_{2}$, the cells on the lower side were fixed in $95 \%$ ethanol and stained with crystal violet at room temperature for $10 \mathrm{~min}$ and counted under a microscope
Table II. Expression of IGFBP7 in colon cancer and tumor-adjacent tissue by IHC (means $\pm \mathrm{SD})$.

\begin{tabular}{lcccc}
\hline Stage & $n$ & $\mathrm{~T}(\mathrm{OD})$ & $\mathrm{N}(\mathrm{OD})$ & P-value \\
\hline I+II & 37 & $0.758 \pm 0.218$ & $0.824 \pm 0.112$ & 0.105 \\
III+IV & 44 & $0.579 \pm 0.231$ & $0.682 \pm 0.191$ & $0.031^{\mathrm{a}}$ \\
\hline
\end{tabular}

${ }^{\mathrm{a}} \mathrm{P}<0.05$. T, colon cancer tissue; $\mathrm{N}$, tumor-adjacent tissue; OD, optical density.

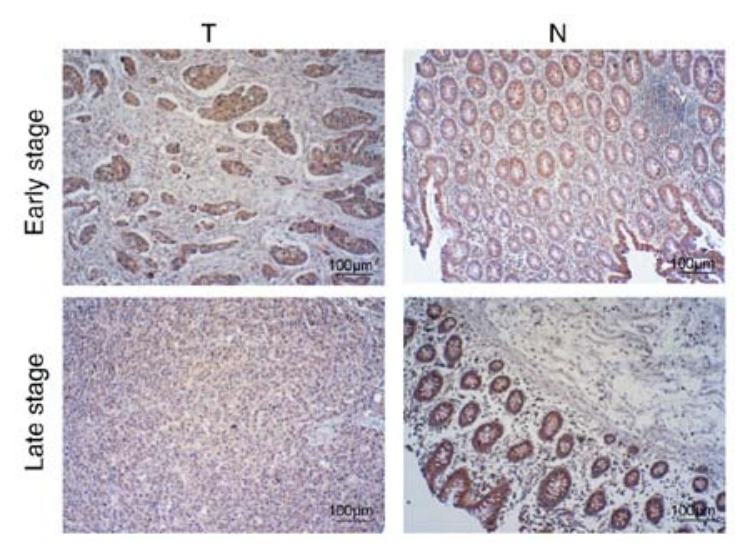

Figure 1. Insulin-like growth factor binding protein 7 expression in one colon adenocarcinoma sample as analyzed by immunohistochemistry. Early stage (I + II) compared with late stage (III + IV). Scale bar, $100 \mu \mathrm{m}$. T, colon cancer tissue, $\mathrm{N}$, tumor adjacent tissue.

(Olympus Corp.). Four microscopic fields were randomly selected for cell counting. The images were captured at x100 magnification. Each experiment was performed at least three times.

Statistical analysis. Data were analyzed with GraphPad Prism 7.0 software (GraphPad Software, Inc.). Data were presented as means \pm SD. Paired t-tests and a Mann-Whitney U test were used. To analyze the results from CRC tissues, comparisons of clinicopathological parameters and EMT markers between the high- and low-IGFBP7 expression groups were performed via $\chi^{2}$ or Fisher's exact tests. Correlations were analyzed using Spearman's coefficient. $\mathrm{P}<0.05$ was considered to indicate a statistically significant difference.

\section{Results}

IGFBP7 is significantly downregulated in LM tissues of patients with $C R C$. IHC was performed using primary CRC tissues with and without metastasis, as well as in matched PC and LM tissues. In all 81 pairs of primary CRC and tumor-adjacent tissue samples, the majority ( $>95 \%$ ) of tumor cells and adjacent mucosa stained positively for IGFBP7. The staining pattern was predominantly cytoplasmic and nuclear staining was observed in only one sample. There were no significant differences in the expression of IGFBP7 between early stage (I + II) CRC and adjacent normal colonic mucosa $(\mathrm{P}=0.285)$; however, late stage (III + IV) CRC revealed a significantly low expression of IGFBP7 compared with adjacent normal colonic mucosa 
Table III. Association between IGFBP7 expression and clinicopathological characteristics in colon cancer by IHC.

\begin{tabular}{|c|c|c|c|c|c|}
\hline \multirow[b]{2}{*}{ Variable } & \multirow[b]{2}{*}{ Total $(n)$} & \multicolumn{2}{|c|}{ IGFBP7 expression } & \multirow[b]{2}{*}{$\mathrm{r}$} & \multirow[b]{2}{*}{ P-value } \\
\hline & & Low n $(\%)$ & High n (\%) & & \\
\hline Age (years) & & & & 0.015 & 1.000 \\
\hline$<60$ & 33 & $16(48.5)$ & $17(54.5)$ & & \\
\hline$\geq 60$ & 72 & 35 (48.6) & $37(51.4)$ & & \\
\hline Sex & & & & -0.002 & 0.326 \\
\hline Male & 57 & $28(49.1)$ & $29(50.9)$ & & \\
\hline Female & 48 & $29(60.4)$ & 19 (39.6) & & \\
\hline Histologic grade & & & & 0.281 & $0.027^{\mathrm{a}}$ \\
\hline Low & 71 & $24(33.8)$ & $47(66.2)$ & & \\
\hline High & 29 & 17 (58.6) & $12(41.4)$ & & \\
\hline Lympho-node metastasis & & & & 0.34 & $0.039^{\mathrm{a}}$ \\
\hline Negative & 41 & $21(51.2)$ & $20(48.8)$ & & \\
\hline Positive & 64 & 46 (71.9) & $18(28.1)$ & & \\
\hline Liver metastasis & & & & 0.537 & $0.002^{\mathrm{a}}$ \\
\hline Negative & 81 & $22(27.2)$ & $59(72.8)$ & & \\
\hline Positive & 24 & $15(62.5)$ & $9(37.5)$ & & \\
\hline TNM stage & & & & 0.410 & $0.040^{\mathrm{a}}$ \\
\hline $\mathrm{I}+\mathrm{II}$ & 37 & $16(43.2)$ & $21(56.8)$ & & \\
\hline III+IV & 68 & 44 (73.3) & $24(35.3)$ & & \\
\hline
\end{tabular}

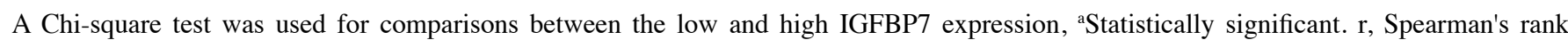
correlation test.

$(\mathrm{P}=0.031$; Table II, Fig. 1). Furthermore, in CRC samples, the low IGFBP7 expression group exhibited significantly higher lymphatic metastasis $(\mathrm{P}=0.039)$, liver metastasis $(\mathrm{P}=0.002)$ and advanced tumor stage $(\mathrm{P}=0.014)$ compared with the high IGFBP7 expression group, which is consistent with a previous study (7). In addition, no significant correlations between IGFBP7 expression and other clinicopathological features, including age, sex, tumor location, tumor size and histological grade, were reported $(\mathrm{P}>0.05$; Table III).

Additionally, 24 of 101 patients had synchronous LM. Of note, IHC analysis of PC and matched LM tissues revealed very low or undetectable expression of IGFBP7 in metastasized CRC tissues compared with matched PC and normal hepatocytes in adjacent tissues (Fig. 2A and B). Furthermore, IGFBP7 expression was gradually reduced at the invasive front, indicating that the suppression of IGFBP7 expression may increase the metastatic potential of CRC cells at the invasive front (Fig. 2B).

Correlation of IGFBP7 and EMT-associated proteins in CRC. To further investigate the association between IGFBP7 expression and EMT-associated proteins, including E-cadherin, $\mathrm{N}$-cadherin and Vimentin, the distribution of the aforementioned proteins was analyzed in PC and matched LM tissues by IHC (Fig. 2C-H). Immunostaining of IGFBP7 and E-cadherin $(\mathrm{r}=0.451, \mathrm{P}=0.015)$ revealed a positive correlation. Conversely, a negative correlation was determined between IGFBP7 and $\mathrm{N}$-cadherin $(\mathrm{r}=-0.381, \mathrm{P}=0.035)$ and Vimentin $(\mathrm{r}=-0.314$, $\mathrm{P}=0.035$ ) in $\mathrm{PC}$ and matched LM tissues (Table IV). In addition, the expression levels of E-cadherin, $\mathrm{N}$-cadherin and Vimentin were investigated by RT-qPCR. The expression levels of IGFBP7 and E-cadherin in LM tissues were significantly decreased compared with $\mathrm{PC}$ tissues $(\mathrm{P}<0.001$ and $\mathrm{P}=0.016$, respectively). By contrast, the expression levels of $\mathrm{N}$-cadherin and Vimentin were significantly increased in matched LM tissues ( $\mathrm{P}=0.041$ and $\mathrm{P}=0.027$, respectively; Fig. 3 ).

Association between the expression of IGFBP7 and markers of EMT in colon cancer cells. To verify the aforementioned findings from CRC tissues and investigate the potential role of the IGFBP7 in colon cancer, the expression of IGFBP7 in CRC cells lines was analyzed by RT-qPCR. LoVo cells exhibited robust IGFBP7 expression, whereas downregulated expression was observed in Caco 2 cells. The expression of IGFBP7 in RKO, HT-29, HCT116, SW620 and SW480 cells was undetectable (Fig. 4A). Similarly the expression of protein by western blotting was confirmed (Fig. 4B).

To further analyze the association between the expression of EMT markers and the potential role of IGFBP7 in colon cancer cells, two colon cancer cell lines, including LoVo cells with robust IGFBP7 expression and HT29 cells with undetectable expression were selected. Then, IGFBP7 was knocked down in LoVo cells and overexpressed in HT-29 cells to examine the functional role of IGFBP7 in EMT. Specifically, LoVo cells were transfected with IGFBP7 shRNA via lentivirus for stable knockdown (IGFBP7-shRNA), which resulted in a $>90 \%$ reduction in IGFBP7 expression by RT-qPCR (Fig. 5A), confirmed in the protein level by western 
Table IV. Correlation between IGFBP7 expression and EMT markers in colon cancer by IHC.

\begin{tabular}{|c|c|c|c|c|c|}
\hline \multirow[b]{2}{*}{ Variable } & \multirow[b]{2}{*}{ Total $(n=24)$} & \multicolumn{2}{|c|}{ IGFBP7 expression } & \multirow[b]{2}{*}{$\mathrm{r}$} & \multirow[b]{2}{*}{ P-value } \\
\hline & & Low n $(\%)$ & High n (\%) & & \\
\hline E-cadherin & & & & 0.451 & $0.015^{\mathrm{a}}$ \\
\hline Negative & 5 & $2(40.0)$ & $3(60.0)$ & & \\
\hline Postive & 19 & $3(15.8)$ & $16(84.2)$ & & \\
\hline $\mathrm{N}$-cadherin & & & & -0.381 & $0.035^{\mathrm{a}}$ \\
\hline Negative & 4 & $1(25.0)$ & $3(75.0)$ & & \\
\hline Positive & 20 & $17(85.0)$ & $3(15.0)$ & & \\
\hline Vimentin & & & & -0.314 & $0.035^{\mathrm{a}}$ \\
\hline Negative & 6 & $3(50.0)$ & $3(50.0)$ & & \\
\hline Positive & 18 & $17(94.4)$ & $1(5.6)$ & & \\
\hline
\end{tabular}


correlation test.


Figure 2. Expression of IGFBP7, E-cadherin, N-cadherin and Vimentin in PC and LM tissues as determined by immunohistochemistry. Expression of (A and B) IGFBP7, (C and D) E-cadherin, (E and F) N-cadherin and (G and H) Vimentin in PC and LM tissues. IGFBP7 was downregulated at the invasive front of the LM site. Scale bar, $100 \mu \mathrm{m}$. IGFBP7, insulin-like growth factor binding protein 7; PC, primary colon cancer; LM, liver metastasis. Blank arrow, front of tumor cells invading the liver. Star, IGFBP7 staining of liver metastases.

blotting (Fig. 5B). Cells of the control group were transfected with a scrambled shRNA via lentivirus to establish an NC. The expression of E-cadherin was significantly downregulated following IGFBP7-knockdown in LoVo cells $(\mathrm{P}=0.007$; Fig. 5C), while that of $\mathrm{N}$-cadherin and Vimentin was upregulated $(\mathrm{P}=0.006$ and $\mathrm{P}=0.019$, respectively) compared with the NC (Fig. 5D and E). By contrast, overexpression of IGFBP7 in HT-29 cells by RT-qPCR (Fig. 6A) and western blotting (Fig. 6B) were associated with upregulated E-cadherin expression $(\mathrm{P}<0.001$; Fig. 6C), whereas the expression levels of $\mathrm{N}$-cadherin and Vimentin were downregulated $(\mathrm{P}=0.031$ and $\mathrm{P}=0.029$, respectively; Fig. $6 \mathrm{D}$ and $\mathrm{E}$ ) compared with the NC. As expected, knockdown of IGFBP7 in LoVo cells demonstrated downregulated E-cadherin expression, while $\mathrm{N}$-cadherin and Vimentin were upregulated compared with the $\mathrm{NC}(\mathrm{P}=0.007$, $\mathrm{P}=0.003$ and $\mathrm{P}=0.019$, respectively; Fig. $7 \mathrm{~A}$ and $\mathrm{B}$ ). E-cadherin was upregulated, while $\mathrm{N}$-cadherin and Vimentin were downregulated in HT-29 following IGFBP7 overexpression $(\mathrm{P}=0.008, \mathrm{P}=0.003$ and $\mathrm{P}=0.029$, respectively; Fig. 7A and $\mathrm{C})$. The data suggested that the expression of IGFBP7 may serve a crucial role to in the induction of the epithelial phenotype and the simultaneous loss of mesenchymal features in CRC cells.

Expression of IGFBP7 affects proliferation and invasive activity. A CCK-8 assay was performed to analyze the effects of IGFBP7 overexpression on the proliferation of HT-29 cells. 

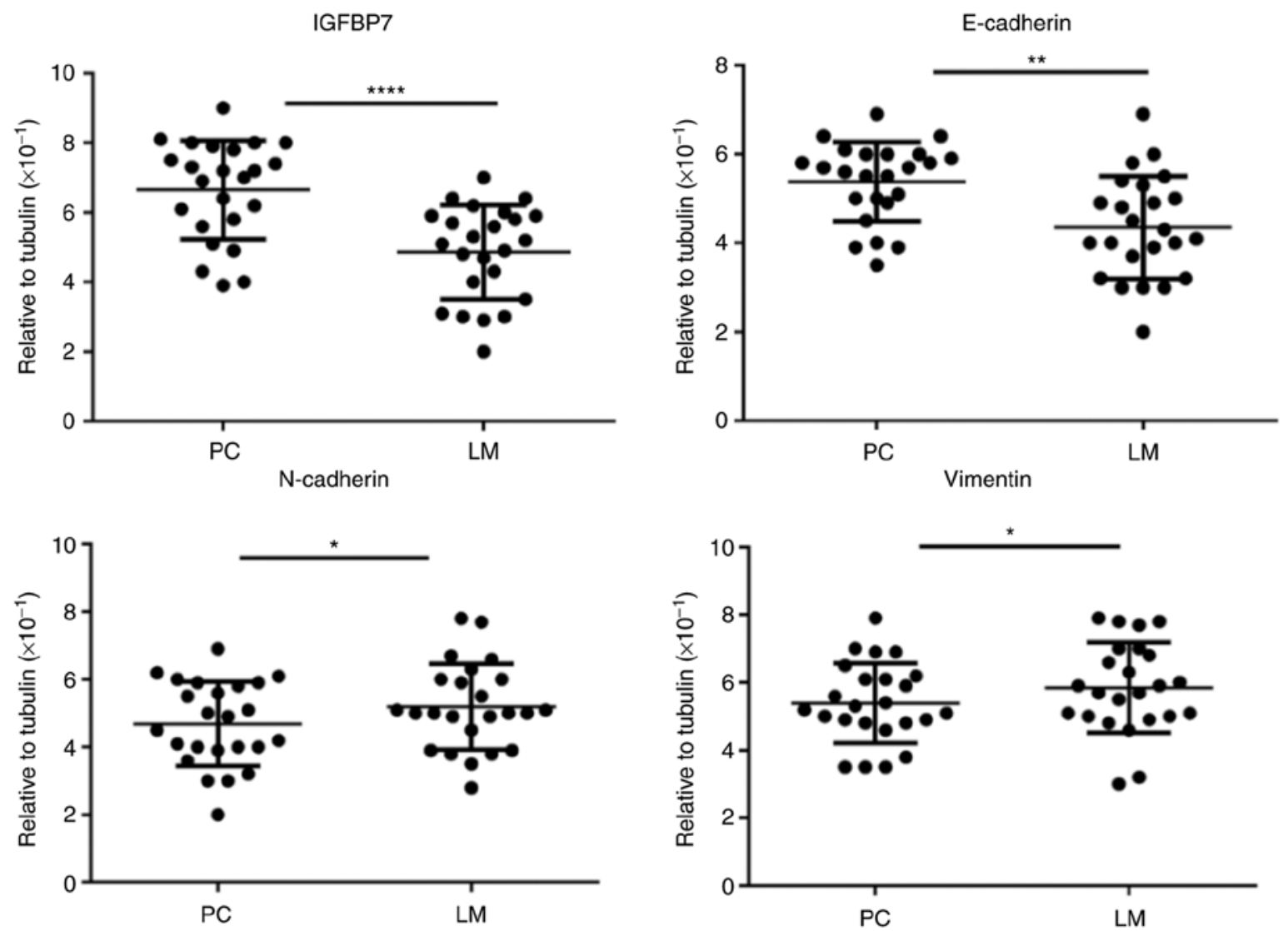

Figure 3. mRNA expression of insulin-like growth factor binding protein 7, E-cadherin, N-cadherin and Vimentin in PC and matched LM tissues as determined by reverse transcription-quantitative polymerase reaction. Grey horizontal bars in each graph represent the mean expression levels. ${ }^{*} \mathrm{P}<0.05$, ${ }^{* *} \mathrm{P}<0.01$ and ${ }^{* * * * *} \mathrm{P}<0.0001$. LM, liver metastasis; PC, primary colon cancer.

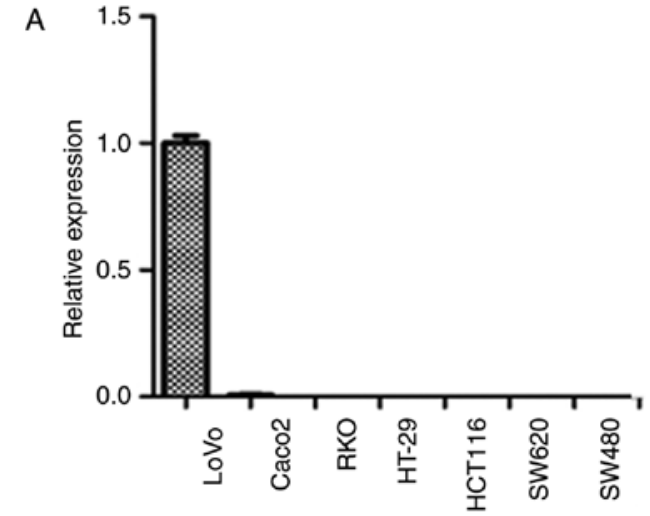

B

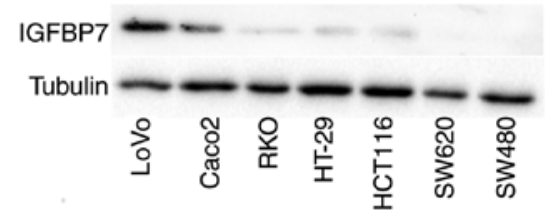

Figure 4. Expression of IGFBP7 in different colon cancer cell lines. (A) IGFBP7 mRNA levels in different colon cancer cell lines. Robust IGFBP7 expression was detected in LoVo cells; however, weak expression was observed in Caco2 cells. The expression of IGFBP7 in RKO, HT29, HCT116, SW620 and SW480 cells was undetectable. (B) IGFBP7 protein levels were confirmed by western blot analysis. IGFBP7, insulin-like growth factor binding protein 7 .

Overexpression of IGFBP7 in HT-29 cells resulted in decreased cell proliferation compared with the empty vector control over a period of 6 days. Its cell viability was significantly lower than that of the NC group at days 4 and $5(\mathrm{P}=0.016$ and $\mathrm{P}=0.002$ ) (Fig. 8A). As IGFBP7 is a secreted protein, cells were treated with $1 \mu \mathrm{g} / \mathrm{IGFBP7}$ recombinant protein to evaluate the effects of IGFBP7 on cell proliferation. The results revealed that cell proliferation was slowly inhibited and the effects of inhibition were noted until the fifth day compared with the blank control group $(\mathrm{P}=0.019)$ (Fig. 8A). Similarly, the proliferation of LoVo cells with IGFBP7 shRNA-mediated knockdown increased until day 5 compared with the $\mathrm{NC}$ groups ( $\mathrm{P}=0.023)$ (Fig. 8B). Conversely, the proliferation of LoVo cells treated with $1 \mu \mathrm{g} / 1$ IGFBP7 markedly increased compared with the blank group but there was no significant difference. The invasive ability of the IGFBP7-overexpressing HT-29 cells was significantly weaker than that of the negative control cells ( $\mathrm{P}=0.008)$ (Fig. 8C), while the invasive ability of LoVo cells with IGFBP7-KD was stronger than that of the negative control cells $(\mathrm{P}=0.006)$ (Fig. 8D).

\section{Discussion}

Approximately $90 \%$ of cancer-associated mortalities are characterized by the metastatic ability of cancer cells to spread from the site of origin and colonize distant organs or nodes (16). The metastatic process has been investigated; the metastasis of various types of cancer has a heterogeneous biology, and may be dependent on certain factors associated with the tissue of origin and region of metastasis (17). Thus, 

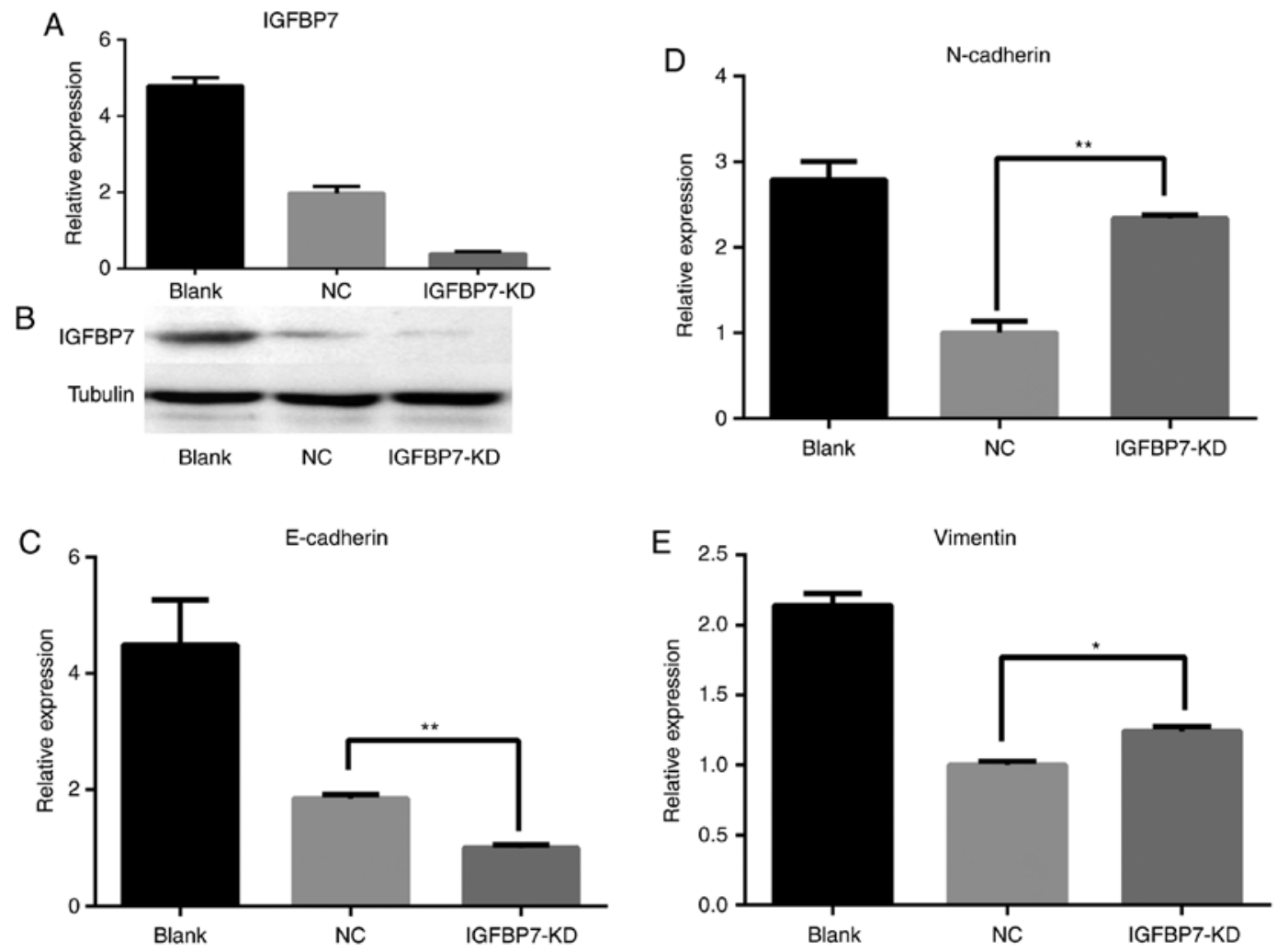

Figure 5. Effects of downregulated IGFBP7 on the expression of E-cadherin, N-cadherin and Vimentin as determined by reverse transcription-quantitative polymerase chain reaction. (A) Insulin-like growth factor binding protein 7 knockdown in LoVo cells at the mRNA level and (B) further confirmed at the protein level. (C) E-cadherin was downregulated, while (D) N-cadherin and (E) Vimentin were significantly upregulated compared with the NC. "P<0.05 and ${ }^{* *} \mathrm{P}<0.01$. Blank, LoVo cells without any treatment. NC, negative control.


Figure 6. Effects of IGFBP7 overexpression on the expression of E-cadherin, N-cadherin and Vimentin as determined by reverse transcription-quantitative polymerase chain reaction. (A) Overexpression of IGFBP7 in HT-29 cells at the mRNA level and (B) further confirmed at the protein level. (C) E-cadherin was upregulated following IGFBP7 overexpression; (D) N-cadherin and (E) Vimentin were downregulated compared with the NC. ${ }^{*} \mathrm{P}<0.05$ and ${ }^{* * * *} \mathrm{P}<0.001$. IGFBP7, insulin-like growth factor binding protein 7; Blank, HT-29 cells without any treatment. NC, negative control. 

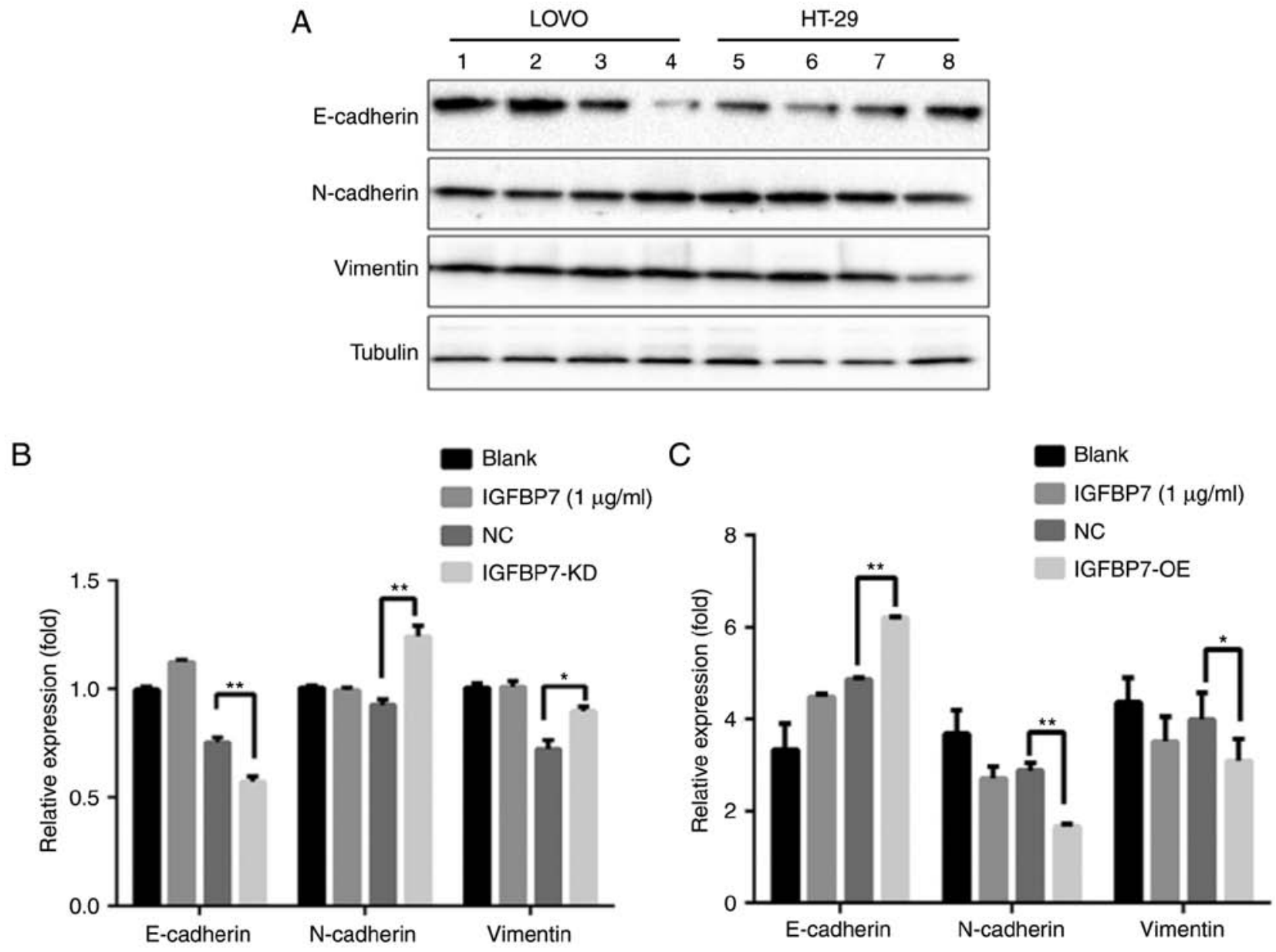

Figure 7. Effects of IGFBP7 knockdown or overexpression in LoVo cells and HT-29 respectively as determined by western blotting. (A) E-cadherin was downregulated, while N-cadherin and Vimentin were significantly upregulated compared with the NC in LoVo cells. In addition, the IGFBP7-treated group $(1 \mu \mathrm{g} / \mathrm{ml})$ exhibited upregulated E-cadherin compared with the blank group; however, no notable variations in the expression of N-cadherin and Vimentin between the blank and IGFBP7-treated groups were observed. In HT-26 cells, E-cadherin was upregulated following IGFBP7 overexpression, while the expression of N-cadherin and Vimentin was downregulated compared with the NC. Lane 1, Blank 2, IGFBP7 3, NC 4, IGFBP7-KD 5, Blank 6, IGFBP7 7, NC 8, IGFBP7-OE. (B) Quantification of protein band intensity in LoVo cells. (C) Quantification of protein band intensity in HT-29 cells. "P<0.05 and ${ }^{* *} \mathrm{P}<0.01$. IGFBP7, insulin-like growth factor binding protein 7; Blank, cells without any treatment; NC, negative control.

it is important to determine the biology of metastasis in various types of cancer. IGFBP7 is a secreted protein that is diffusely expressed in gastrointestinal tract tissues (18), the ovaries (19) and liver (20). The present study investigated the role of IGFBP7 in the progression of CRC from a primary state to the development of metastatic disease, and highlights the importance of IGFBP7 downregulation in LMs originating from CRC. To the best of our knowledge, the present study is the first to directly analyze the expression of IGFBP7 in PC and matched LM tissues. The results revealed IGFBP7 downregulation in LM tissues compared with PC tissues. Of note, IGFBP7 was significantly downregulated in the invasive front of LM tissues, which may promote cell behaviors that facilitate dissemination from the tumor. Furthermore, the potential mechanism by which IGFBP7 serves a pivotal role in the process of LM was investigated.

In the process of metastasis, CRC cells initially lose their epithelial phenotype while simultaneously acquiring the mesenchymal characteristics required for EMT. Numerous studies have highlighted the vital role of EMT in the progression of cancer due to its invasive and metastatic behaviors (21-23).
To the best of our knowledge, only one study has investigated the association between IGFBP7 with EMT, in which IGFBP7 inhibited EMT and tumor metastasis by suppressing transforming growth factor- $\beta$-mediated EMT via the Smad signaling cascade (24). However, the differential expression of IGFBP7 between PC and LM was not determined.

In the present study, it was demonstrated that the downregulation of IGFBP7 from PC to LM tissue was correlated with decreased E-cadherin, and increased N-cadherin and Vimentin expression, suggesting a negative role for IGFBP7 in regulating colon cancer cell invasion via EMT. In addition, several studies have reported the effects of IGFBP7 overexpression on suppressing the growth, invasion and migration of cancer cells. Of note, one study revealed IGFBP7 upregulation during the process of homing into the liver from as early as 3 days; however, the expression thereof returned to basal levels thereafter in a rat model (25). Those findings are inconsistent with the observations of the present study as IGFBP7 was significantly downregulated in LM tissues compared with in PC tissues. This suggests that the expression of IGFBP7 is tightly regulated by its microenvironment. In addition, we noted blood vessels, fibroblasts in stromal tissues, showing 
A

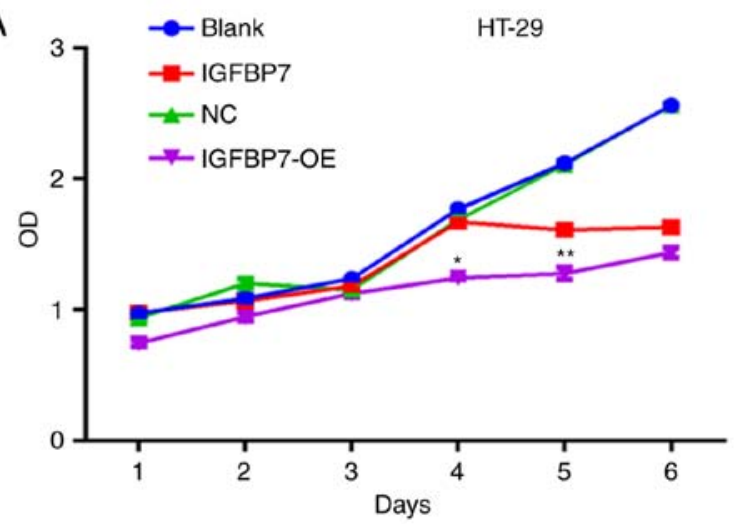

C

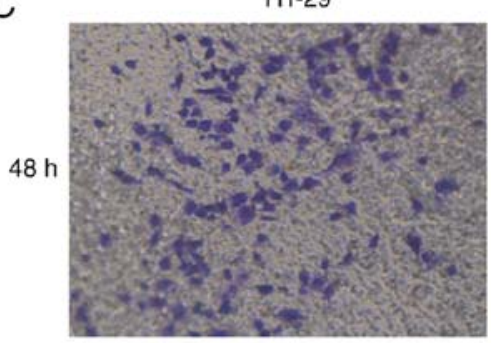

LoVo

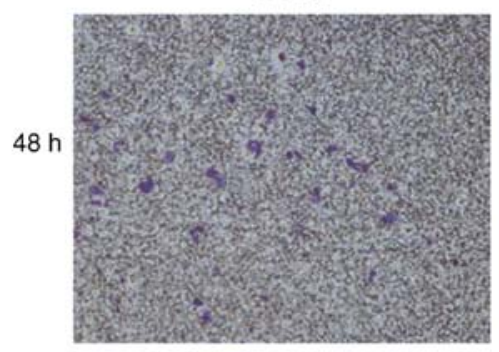

IGFBP7-OE

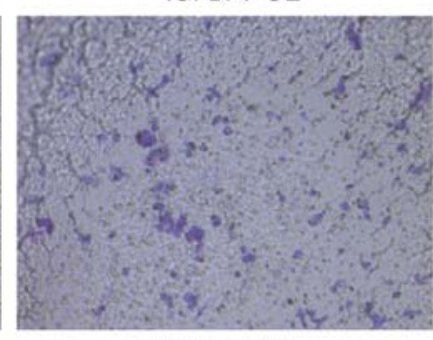

IGFBP7-KD

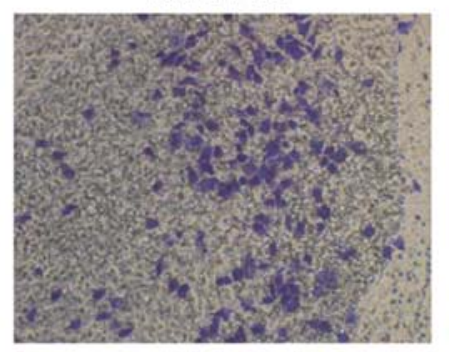

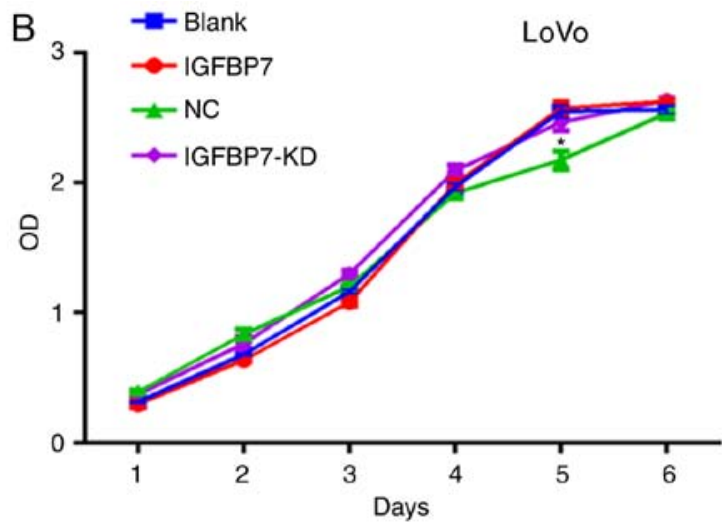

HT-29

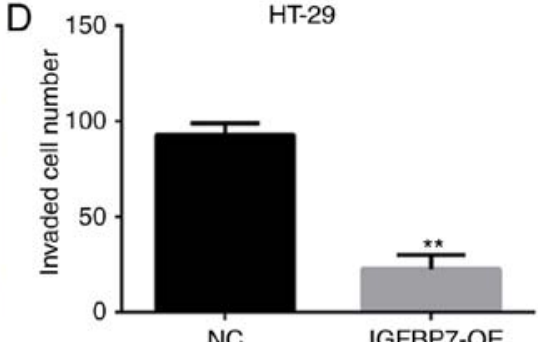

NC

LoVo



Figure 8. Effects of IGFBP7 expression on cell proliferation and invasive activity. (A) Cell Counting Kit-8 proliferation assay showed that overexpression of IGFBP7 in HT-29 cells resulted in decreased cell proliferation compared with the empty vector control over a period of 6 days. Its cell viability is significantly lower than that of the $\mathrm{NC}$ group at day 4 and 5 ( $\mathrm{P}=0.016$ and $\mathrm{P}=0.002$, respectively). IGFBP7 recombinant protein $(1 \mu \mathrm{g} / \mathrm{ml})$ was applied to HT-29 cells to evaluate cell proliferation. Gradual reductions in cell viability were observed, but notable decreases were noted until day 5 compared with the blank control group ( $\mathrm{P}=0.019)$. (B) Cell proliferation of LoVo cells with IGFBP7 shRNA-mediated knockdown was enhanced until day 5 compared to the NC group ( $\mathrm{P}=0.023)$; however, the proliferation of LoVo cells treated with $1 \mu \mathrm{g} / \mathrm{ml}$ IGFBP7 was not significantly promoted compared to the blank group. (C) Invasion assays for HT-29 and LoVo cells. The invasion activity was markedly altered in IGFBP7-KD or IGFBP7-OE cells (x100). (D) Quantification of invaded cell number. ${ }^{*} \mathrm{P}<0.05$ and $^{* *} \mathrm{P}<0.01$. IGFBP7, insulin-like growth factor binding protein 7; Blank, Cells without any treatment. NC, negative control.

IGFBP7-positive staining. IGFBP7 has been studied as a modulator of angiogenesis and was found to inhibit tumor angiogenesis in several contexts $(11,26)$. To a certain degree, it is supposed that IGFBP7 plays a role as mediator for tumor-stroma interactions.

Notably, the majority of colon cancer cell lines used in the present study, including HCT116, SW620, RKO and Caco2 revealed undetectable IGFBP-7 expression by RT-qPCR. By contrast, the LoVo cell line exhibited the highest expression levels of IGFBP7 compared with the aforementioned cell lines. One possible reason is that IGFBP7 is completely or strongly methylated in those cells except LoVo cells, where relatively weak methylation was found (27). Furthermore, inconsistent with the findings in the colon cancer cell lines in this study, the expression of IGFBP7 has been detected in the majority of colon cancer and adjacent normal tissues, though its expression varies across these cells. In addition, tumor xenografts generated by direct intravenous injection of prostate cell lines, $\mathrm{LNCaP}$ or $\mathrm{C} 4-2$, into the bone marrow space resulted in tumors that stained positively for IGFBP-7; however, IGFBP7 was undetected in these cells lines in vitro (28). This indicated that the expression of IGFBP-7 may be induced in vivo within an appropriate host environment. Alterations in the expression of IGFBP7 were reported in the present study. Upregulated expression at early Union for International Cancer Control (UICC) stages was observed, followed by a plateau and a decrease at the most advanced tumor stage IV, which suggests the variable role of the IGFBP7 in CRC.

As the varying expression of IGFBP7 at different UICC stages and the role of IGFBP7 in LM in CRC remain unknown, the present study investigated a possible mechanism underlying the regulation of IGFBP7 expression in metastasis. The expression of IGFBP7 was positively associated with that of E-cadherin, but was negatively associated with $\mathrm{N}$-cadherin and Vimentin in colon cancer tissues compared with matching LM tissues. Of note, cells at the invasive tumor front in LM tissues exhibited downregulated IGFBP7 expression, which was accompanied with the loss of epithelial markers, such as E-cadherin and cell-cell junctions, and a gain in the expression of mesenchymal markers. 
It has been suggested that cancer cells undergo EMT in the PC site to facilitate the invasion and dissemination of a tumor; this process is then reversed and is termed the mesenchymal-epithelial transition (MET) in LM, for clonal outgrowth at metastatic sites (29). It is difficult to determine whether EMT or MET occurs during the development of LM from primary tumors. In the present study, the expression of E-cadherin was downregulated, while that of $\mathrm{N}$-cadherin and Vimentin were upregulated in matched LM tissues compared with in PC samples. This is inconsistent with the findings reported by Hur et al (30). This may be accounted for by the use of synchronous LM tissues in the present study, which are considered to have poorer prognosis compared with patients with metachronous LM. In addition, MET is not required in the process of tumor cell migration from the PC site to the liver due failed cell cycle arrest upon the induction of EMT, leading to genomic instability (31). This instability may result in highly metastatic tumors that are resistant to next-line therapies $(32,33)$. Thus, the results of the present study may provide insight into the behavior of tumors in synchronous LM tissues; however, the specific mechanism remains unknown (34). Analysis of LM tissues indicated the enhanced invasion and dissemination of tumors compared with that in metachronous LM. Furthermore, these properties may be associated with the varied expression of E-cadherin, $\mathrm{N}$-cadherin and Vimentin in the same sample cohort observed in the present study. Thus, minor differences in the expression of E-cadherin, $\mathrm{N}$-cadherin and Vimentin between PC and LM tissues may occur as it is difficult to determine which regions of tissue express EMT-associated proteins prior to collection.

In summary, the findings of the present study indicated that IGFBP7 overexpression leads to the direct targeting of EMT-associated genes, which in turn regulates the metastatic behavior of colon cancer cells. These data suggest the biological and clinical importance of IGFBP7 in CRC; however, the role of IGFBP7 in CRC-associated LM requires further investigation. In addition, downregulation of IGFBP7 in PC associated with the development of LM may facilitate the proliferation and expansion of CRC cells.

\section{Acknowledgements}

The authors wish to thank Professor Shao Lee (School of Life Sciences, Shanxi University, China) for critically reviewing the manuscript in advance of submission.

\section{Funding}

No funding was received.

\section{Availability of data and materials}

All data generated or analyzed during this study are included in this article or are available from the corresponding author on reasonable request.

\section{Authors' contributions}

YLi and LL contributed to the study design and wrote the manuscript. YX, GZ, JJ and HH performed the sample collection and data analysis. YLi, YLiu and YG performed the experiments. All authors read and approved the final manuscript.

\section{Ethics approval and consent to participate}

Written informed consent was obtained from all patients prior to enrolment. All procedures were conducted in accordance with standard guidelines for the Study of Humans and were approved by the Research Ethics Committee of First Hospital of Shanxi Medical University.

\section{Patient consent for publication}

Not applicable.

\section{Competing interests}

The authors declare that they have no competing interests.

\section{References}

1. Miller KD, Siegel RL, Lin CC, Mariotto AB, Kramer JL, Rowland JH, Stein KD, Alteri R and Jemal A: Cancer treatment and survivorship statistics, 2016. CA Cancer J Clin 66: 271-289, 2016.

2. Wale A, Van Cutsem E, Rao S, Cunningham D and Brown G: Session 2: Synchronous metastatic disease-liver first or primary first? The oncologist decides. Colorectal Dis 20 (Suppl 1): S52-S55, 2018.

3. Loret N, Denys H, Tummers P and Berx G: The role of epithelial-to-mesenchymal plasticity in ovarian cancer progression and therapy resistance. Cancers (Basel) 11: E838, 2019.

4. Blick T, Widodo E, Hugo H, Waltham M, Lenburg ME, Neve RM and Thompson EW: Epithelial mesenchymal transition traits in human breast cancer cell lines. Clin Exp Metastasis 25: 629-642, 2008.

5. Bastid J: EMT in carcinoma progression and dissemination: Facts, unanswered questions, and clinical considerations. Cancer Metastasis Rev 31: 277-283, 2012.

6. Gomes LR, Terra LF, Sogayar MC and Labriola L: Epithelial-mesenchymal transition: Implications in cancer progression and metastasis. Curr Pharm Biotechnol 12: 1881-1890, 2011.

7. Brabletz T, Kalluri R, Nieto MA and Weinberg RA: EMT in cancer. Nat Rev Cancer 18: 128-134, 2018.

8. Brabletz T: To differentiate or not-routes towards metastasis. Nat Rev Cancer 12: 425-436, 2012.

9. Yamanaka Y, Wilson EM, Rosenfeld RG and Oh Y: Inhibition of insulin receptor activation by insulin-like growth factor binding proteins. J Biol Chem 272: 30729-30734, 1997.

10. Ruan W, Xu E, Xu F, Ma Y, Deng H, Huang Q, Lv B, Hu H, Lin J, Cui J, et al: IGFBP7 plays a potential tumor suppressor role in colorectal carcinogenesis. Cancer Biol Ther 6: 354-359, 2007.

11. Tamura K, Hashimoto K, Suzuki K, Yoshie M, Kutsukake M and Sakurai T: Insulin-like growth factor binding protein-7 (IGFBP7) blocks vascular endothelial cell growth factor (VEGF)-induced angiogenesis in human vascular endothelial cells. Eur J Pharmacol 610: 61-67, 2009.

12. Benatar T, Yang W, Amemiya Y, Evdokimova V, Kahn H, Holloway $\mathrm{C}$ and Seth A: IGFBP7 reduces breast tumor growth by induction of senescence and apoptosis pathways. Breast Cancer Res Treat 133: 563-573, 2012.

13. Evdokimova V, Tognon CE, Benatar T, Yang W, Krutikov K, Pollak M, Sorensen PH and Seth A: IGFBP7 binds to the IGF-1 receptor and blocks its activation by insulin-like growth factors. Sci Signal 5: ra92, 2012.

14. Zlobec I, Terracciano L, Jass JR and Lugli A: Value of staining intensity in the interpretation of immunohistochemistry for tumor markers in colorectal cancer. Virchows Arch 451: 763-769, 2007.

15. Livak KJ and Schmittgen TD: Analysis of relative gene expression data using real-time quantitative PCR and the 2(-Delta Delta C(T)) method. Methods 25: 402-408, 2001.

16. Gupta GP and Massagué J: Cancer metastasis: Building a framework. Cell 127: 679-695, 2006. 
17. Joyce JA and Pollard JW: Microenvironmental regulation of metastasis. Nat Rev Cancer 9: 239-252, 2009.

18. Takeno A, Takemasa I, Doki Y, Yamasaki M, Miyata H, Takiguchi S, Fujiwara Y, Matsubara K and Monden M: Integrative approach for differentially overexpressed genes in gastric cancer by combining large-scale gene expression profiling and network analysis. Br J Cancer 99: 1307-1315, 2008.

19. Gambaro K, Quinn MC, Cáceres-Gorriti KY, Shapiro RS, Provencher D, Rahimi K, Mes-Masson AM and Tonin PN: Low levels of IGFBP7 expression in high-grade serous ovarian carcinoma is associated with patient outcome. BMC Cancer 15: 135, 2015.

20. Tomimaru Y, Eguchi H, Wada H, Kobayashi S, Marubashi S, Tanemura M, Umeshita K, Kim T, Wakasa K, Doki Y, et al: IGFBP7 downregulation is associated with tumor progression and clinical outcome in hepatocellular carcinoma. Int J Cancer 130: 319-327, 2012.

21. Liao TT and Yang MH: Revisiting epithelial-mesenchymal transition in cancer metastasis: The connection between epithelial plasticity and stemness. Mol Oncol 11: 792-804, 2017

22. Cao H, Xu E, Liu H, Wan L and Lai M: Epithelial-mesenchymal transition in colorectal cancer metastasis: A system review. Pathol Res Pract 211: 557-569, 2015

23. Heerboth S, Housman G, Leary M, Longacre M, Byler S, Lapinska K, Willbanks A and Sarkar S: EMT and tumor metastasis. Clin Transl Med 4: 6, 2015.

24. Zhu S, Zhang J, Xu F, Xu E, Ruan W, Ma Y, Huang Q and Lai M: IGFBP-rP1 suppresses epithelial-mesenchymal transition and metastasis in colorectal cancer. Cell Death Dis 6: e1695, 2015.

25. Georges RB, Adwan H, Hamdi H, Hielscher T, Linnemann U and Berger MR: The insulin-like growth factor binding proteins 3 and 7 are associated with colorectal cancer and liver metastasis Cancer Biol Ther 12: 69-79, 2011.

26. Hooper AT, Shmelkov SV, Gupta S, Milde T, Bambino K, Gillen K, Goetz M, Chavala S, Baljevic M, Murphy AJ, et al: Angiomodulin is a specific marker of vasculature and regulates vascular endothelial growth factor-A-dependent neoangiogenesis. Circ Res 105: 201-208, 2009.
27. Suzuki H, Igarashi S, Nojima M, Maruyama R, Yamamoto E, Kai M, Akashi H, Watanabe Y, Yamamoto H, Sasaki Y, et al: IGFBP7 is a p53-responsive gene specifically silenced in colorectal cancer with $\mathrm{CpG}$ island methylator phenotype. Carcinogenesis 31: 342-349, 2010.

28. Long TJ, Sprenger CC, Plymate SR and Ratner BD: Prostate cancer xenografts engineered from $3 \mathrm{D}$ precision-porous poly(2-hydroxyethyl methacrylate) hydrogels as models for tumorigenesis and dormancy escape. Biomaterials 35: 8164-8174, 2014.

29. Thiery JP: Epithelial-mesenchymal transitions in tumour progression. Nat Rev Cancer 2: 442-454, 2002.

30. Hur K, Toiyama Y, Takahashi M, Balaguer F, Nagasaka T, Koike J, Hemmi H, Koi M, Boland CR and Goel A: MicroRNA-200c modulates epithelial-to-mesenchymal transition (EMT) in human colorectal cancer metastasis. Gut 62: 1315-1326, 2013

31. Comaills V, Kabeche L, Morris R, Buisson R, Yu M, Madden MW, LiCausi JA, Boukhali M, Tajima K, Pan S, et al: Genomic instability is induced by persistent proliferation of cells undergoing epithelial-to-mesenchymal transition. Cell Rep 17: 2632-2647, 2016.

32. Sun Y, Campisi J, Higano C, Beer TM, Porter P, Coleman I, True L and Nelson PS: Treatment-induced damage to the tumor microenvironment promotes prostate cancer therapy resistance through WNT16B. Nat Med 18: 1359-1368, 2012.

33. Creighton CJ, Li X, Landis M, Dixon JM, Neumeister VM, Sjolund A, Rimm DL, Wong H, Rodriguez A, Herschkowitz JI, et al: Residual breast cancers after conventional therapy display mesenchymal as well as tumor-initiating features. Proc Natl Acad Sci USA 106: 13820-13825, 2009.

34. Adam R, de Gramont A, Figueras J, Kokudo N, Kunstlinger F, Loyer E, Poston G, Rougier P, Rubbia-Brandt L, Sobrero A, et al: Managing synchronous liver metastases from colorectal cancer: A multidisciplinary international consensus. Cancer Treat Rev 41: 729-741, 2015.

This work is licensed under a Creative Commons Attribution-NonCommercial-NoDerivatives 4.0 International (CC BY-NC-ND 4.0) License. 